\title{
Underweight but not overweight is associated with excess mortality in septic ICU patients
}

\author{
Thomas Danninger · Richard Rezar (D) - Behrooz Mamandipoor · Daniel Dankl · Andreas Koköfer · Christian Jung • \\ Bernhard Wernly · Venet Osmani
}

Received: 20 March 2021 / Accepted: 25 June 2021 / Published online: 16 September 2021

(C) The Author(s) 2021

\begin{abstract}
Summary
Background Higher survival has been shown for overweight septic patients compared with normal or underweight patients in the past. This study aimed at investigating the management and outcome of septic ICU patients in different body mass index (BMI) categories in a large multicenter database.

Methods In total, 16,612 patients of the eICU collaborative research database were included. Baseline characteristics and data on organ support were
\end{abstract}

The authors Thomas Danninger, Richard Rezar, Bernhard Wernly and Venet Osmani contributed equally to the manuscript.

Availability of data and material: All data relevant for this study will be given by the authors upon specific request. Patients or the public were not involved in the design, or conduct, or reporting, or dissemination plans of the research.

T. Danninger, M.D. · D. Dankl, M.D. · A. Koköfer, M.D. · B. Wernly, M.D., Ph.D.

Department of Anaesthesiology, Perioperative Medicine and Intensive Care Medicine, Paracelsus Medical University of Salzburg, Salzburg, Austria

R. Rezar, M.D. $(\varangle) \cdot$ B. Wernly, M.D., Ph.D.

Department of Cardiology, Intensive Care Medicine \& Emergency Department, Paracelsus Medical University of Salzburg, 5020 Salzburg, Austria

r.rezar@salk.at

B. Mamandipoor, M.Sc. · V. Osmani, Ph.D.

Fondazione Bruno Kessler Research Institute, Trento, Italy

C. Jung, M.D., Ph.D.

Medical Faculty, Division of Cardiology, Pulmonology and

Vascular Medicine, University Hospital Düsseldorf,

Heinrich-Heine-University Düsseldorf, Düsseldorf, Germany

B. Wernly, M.D., Ph.D.

Center for Public Health and Healthcare Research,

Paracelsus Medical University of Salzburg, Salzburg, Austria documented. Multilevel logistic regression analysis was performed to fit three sequential regression models for the binary primary outcome (ICU mortality) to evaluate the impact of the BMI categories: underweight $\left(<18.5 \mathrm{~kg} / \mathrm{m}^{2}\right)$, normal weight $\left(18.5\right.$ to $\left.<25 \mathrm{~kg} / \mathrm{m}^{2}\right)$, overweight $\left(25\right.$ to $\left.<30 \mathrm{~kg} / \mathrm{m}^{2}\right)$ and obesity $\left(\geq 30 \mathrm{~kg} / \mathrm{m}^{2}\right)$. Data were adjusted for patient level characteristics (model 2) as well as management strategies (model 3).

Results Management strategies were similar across BMI categories. Underweight patients evidenced higher rates of ICU mortality. This finding persisted after adjusting in model 2 (aOR 1.54, 95\% CI 1.15-2.06; $p=0.004$ ) and model 3 (aOR 1.57, 95\%CI 1.16-2.12; $p=0.003$ ). No differences were found regarding ICU mortality between normal and overweight patients (aOR 0.93, 95\%CI 0.81-1.06; $p=0.29$ ). Obese patients evidenced a lower risk of ICU mortality compared to normal weight, a finding which persisted across all models (model 2: aOR 0.83, 95\%CI 0.69-0.99; $p=0.04$; model 3: aOR 0.82, 95\%CI 0.68-0.98; $p=0.03$ ). The protective effect of obesity and the negative effect of underweight were significant in individuals $>65$ years only.

Conclusion In this cohort, underweight was associated with a worse outcome, whereas obese patients evidenced lower mortality. Our analysis thus supports the thesis of the obesity paradox.

Keywords Sepsis - Intensive care - Critically ill · BMI · Obesity paradox $\cdot$ Fluid management

\section{Introduction}

Both overfeeding and undernourishment are highly relevant challenges for public healthcare systems worldwide [1]. Obesity is known to be associated with low-grade chronic inflammation and cardiometabolic 
diseases [2]. It also goes hand in hand with a higher risk for infections and sepsis, which is another common clinical challenge associated with high morbidity and mortality [3-5]. A better understanding of subgroups at higher risk could therefore contribute to improved patient care [6-11]. The pathogenesis and optimal treatment of septic patients is the subject of intensive research, whereas mortality remains high and an often limited functional capacity in surviving patients remains a challenge [6, 12-14]. Underweight is a less common problem than overweight in Western societies. Yet, the relationship between sepsis and underweight is of great interest from a clinical perspective as undernourished septic patients have been consistently observed to suffer from excess mortality [15-17]. On the contrary, the association of sepsis with obesity is complex. While adipose patients have a higher incidence of sepsis, an obesity paradox was observed by different authors [5, 18-20]. This refers to the phenomenon that adipose septic patients, contrary to the experience with many other (chronic) diseases, have a better survival rate than normal or underweight patients [21]. The phenomenon that obesity is a risk factor for the occurrence of a critical illness on the one hand but acutely ill obese patients have a better outcome on the other hand, has also been observed in other clinical situations and remains subject of current debate [22]. Since data on the relationship between obesity and sepsis in particular are contradictory and often based on single center studies, we wanted to investigate the relationship between body mass index (BMI) and mortality in septic patients in a large, multicenter database. The aim of our paper was to evaluate possible associations of overweight and underweight with the outcome of septic patients. We conducted this analysis in the large-scale eICU collaborative research database [23].

\section{Methods}

\section{Study subjects}

The eICU collaborative research database is a multicenter ICU database, including over 200,000 admissions on 335 ICUs from 208 hospitals across the USA in 2014 and 2015 [23]. We extracted baseline characteristics and organ support data (use of vasopressors and mechanical ventilation) on day one. The database is released under the Health Insurance Portability and Accountability Act (HIPAA) safe harbor provision. Septic patients in this study were identified via the method established by Pollard et al. [23]. Elixhauser Comorbidity Index was calculated using the Agency for Healthcare Research and Quality (AHRQ) method [24, 25].

\section{Statistical analysis}

We expressed continuous data points as median \pm interquartile range and assessed differences between independent groups using Kruskal-Wallis equality of populations rank test accordingly. Categorical data are expressed as numbers (percentage), $\chi^{2}$-test was used to calculate univariate differences between groups. The primary exposure was BMI as an ordinal variable based on the World Health Organization BMI classification: underweight $\left(\mathrm{BMI}<18.5 \mathrm{~kg} / \mathrm{m}^{2}\right)$, normal weight (BMI 18.5 to $<25 \mathrm{~kg} / \mathrm{m}^{2}$ ), overweight (BMI 25 to $\left.<30 \mathrm{~kg} / \mathrm{m}^{2}\right)$ and obesity $\left(B M I \geq 30 \mathrm{~kg} / \mathrm{m}^{2}\right)$. The primary outcome was ICU mortality. The secondary outcomes were management strategies, mechanical ventilation, and vasopressor use. We used multilevel logistic regression to fit three sequential regression models for the binary primary outcome to evaluate the impact of the BMI category on ICU mortality. First, a baseline model with the BMI category as a fixed effect and ICU as random effect (model 1) was fitted. Second, to model 1, patient characteristics (age, sequential organ failure assessment, SOFA, score, sex, infection source, ethnics, model 2) were added as independent variables to the model. Third, to model 2, management strategies (model 3) were added to the model. Model 1 and model 2 were used to evaluate the primary and secondary outcomes, whereas model 3 was only used to assess the primary outcomes. We chose the independent variables based on our clinical experience. We calculated adjusted odds ratios (aOR) with respective 95\% confidence intervals (95\% CI). Additionally, we performed sensitivity analyses, stratifying patients with received fluids $>30 \mathrm{ml} / \mathrm{kg} / \mathrm{h}$, creatinine above and below $2.0 \mathrm{mg} / \mathrm{dL}$ (arbitrary cut-off), lactate above and below $2.0 \mathrm{mmol} / \mathrm{L}$ (arbitrary cut-off), age above and below 65 years (arbitrary cut-off), and SOFA score above and below 10 points (arbitrary cut-off), with and without mechanical ventilation, with and without vasopressor use, and patients with a primary pulmonary focus versus non-pulmonary/all other foci. We performed the stratified sensitivity analyses using model 1. All tests were two-sided, and a $p$ value of $<0.05$ was considered statistically significant. Stata/IC 16.1 (StataCorp LLC 2019. Stata Statistical Software: Release 16. College Station, TX, USA) was used for all statistical analyses.

\section{Results}

In total, 16,612 septic patients were included in this analysis, whereas 964 (6\%) patients were underweight, 5219 (31\%) were of normal weight, $4402(26 \%)$ were overweight and 6027 (36\%) were obese. The baseline characteristics are shown in Tables 1 and 2 . Obese patients tended to be younger $(64+19$ years vs. $68+23$ years; $p=0.001)$ but had SOFA scores $>10$ ( $14 \%$ vs. $12 \% ; p<0.001)$ more often; however, the most likely clinically relevant differences between the groups were the higher rates of lactate concentrations above $2.0 \mathrm{mmol} / \mathrm{L}$ in underweight patients ( $47 \%$ in underweight vs. $44 \%$ in normal weight patients) and the higher rates of creatinine concentrations $>2.0 \mathrm{mg} / \mathrm{dL}$ 
Table 1 Baseline characteristics in the total cohort stratified for BMI categories

\begin{tabular}{|c|c|c|c|c|c|}
\hline Characteristic & Underweight & Normal weight & Overweight & Obesity & $p$-value \\
\hline & $n=964$ & $n=5219$ & $n=4402$ & $n=6027$ & \\
\hline \multicolumn{6}{|l|}{ Anthropometric data } \\
\hline $\mathrm{BMI}$ in $\mathrm{kg} / \mathrm{m}^{2}$, median (IQR) & 17 (2) & $23(3)$ & $27(2)$ & $36(9)$ & $<0.001^{*}$ \\
\hline Age in years, median (IQR) & $66(24)$ & $68(23)$ & $68(21)$ & $64(19)$ & $<0.001^{*}$ \\
\hline Age $>65$ years, $n(\%)$ & $489(51)$ & $2,925(56)$ & $2479(56)$ & $2814(47)$ & $<0.001^{*}$ \\
\hline Elixhauser Comorbidity Index, median (IQR) & $3(10)$ & $0(10)$ & $0(10)$ & $0(9)$ & $0.003^{*}$ \\
\hline \multicolumn{6}{|l|}{ Risk parameter } \\
\hline SOFA score points, median (IQR) & $5(5)$ & $6(5)$ & $5(5)$ & $6(6)$ & $0.004^{*}$ \\
\hline SOFA score > 10 points, $n(\%)$ & $106(11)$ & 638 (12) & $573(13)$ & $861(14)$ & $0.002^{*}$ \\
\hline Heart rate $>110 \mathrm{bpm}, n(\%)$ & $283(31)$ & $1347(27)$ & $1145(28)$ & $1368(25)$ & $<0.001^{*}$ \\
\hline Body temperature $>38^{\circ} \mathrm{C}, n(\%)$ & $87(10)$ & $500(10)$ & $516(12)$ & $769(13)$ & $<0.001^{*}$ \\
\hline \multicolumn{6}{|l|}{ Biomarkers } \\
\hline Creatinine mg/dL, median (IQR) & $1.0(1.2)$ & $1.1(1.3)$ & $1.3(1.4)$ & $1.5(1.6)$ & $<0.001^{*}$ \\
\hline Creatinine $>2.0 \mathrm{mg} / \mathrm{dL}, n(\%)$ & $193(22)$ & $1226(25)$ & $1196(29)$ & $2035(36)$ & $<0.001^{*}$ \\
\hline Lactate mmol/L, median (IQR) & $1.9(2.2)$ & $1.8(1.9)$ & $1.8(1.8)$ & $1.8(1.8)$ & 0.12 \\
\hline Lactate $>2.0 \mathrm{mmol} / \mathrm{L}, n(\%)$ & $255(47)$ & $1358(44)$ & $1135(43)$ & $1530(42)$ & 0.14 \\
\hline Length of stay in $\mathrm{h}$ & & & & & $<0.001^{*}$ \\
\hline$<72 \mathrm{~h}, n(\%)$ & $610(63)$ & $3304(63)$ & $2790(63)$ & $3657(61)$ & - \\
\hline $72-168 \mathrm{~h}, n(\%)$ & $257(27)$ & $1255(24)$ & $1065(24)$ & $1524(25)$ & - \\
\hline$>168 \mathrm{~h}, n(\%)$ & $97(10)$ & $660(13)$ & $547(12)$ & $846(14)$ & - \\
\hline \multicolumn{6}{|l|}{ Fluid management in first $24 \mathrm{~h}$} \\
\hline Total amount of fluids in ml, median (IQR) & $2730(3316)$ & 2725 (2885) & $2684(2896)$ & $2673(2881)$ & $<0.001^{*}$ \\
\hline Amount of fluid per kg bodyweight in ml, median (IQR) & $57(67)$ & $43(47)$ & $34(37)$ & $25(30)$ & $<0.001^{*}$ \\
\hline Amount of fluid per $\mathrm{kg} \mathrm{BW}>30 \mathrm{ml} / \mathrm{kg} / \mathrm{h}, n(\%)$ & $322(71)$ & $1700(65)$ & $1235(57)$ & $1253(42)$ & $<0.001^{*}$ \\
\hline
\end{tabular}

Table 2 Baseline characteristics in the total cohort stratified for BMI categories

\begin{tabular}{|c|c|c|c|c|c|}
\hline \multirow[t]{2}{*}{ Characteristic } & Underweight & Normal weight & Overweight & Obesity & $p$-value \\
\hline & $n=964, n(\%)$ & $n=5219, n(\%)$ & $n=4402, n(\%)$ & \multicolumn{2}{|l|}{$n=6027, n(\%)$} \\
\hline \multicolumn{6}{|l|}{ Infectious focus } \\
\hline UTI & $179(19)$ & $1,162(22)$ & $1,019(23)$ & $1,490(25)$ & $<0.001^{*}$ \\
\hline Pulmonary & $455(47)$ & $2,138(41)$ & $1,600(36)$ & 2,035 (34) & $<0.001^{*}$ \\
\hline GI & $97(10)$ & $689(13)$ & $603(14)$ & $657(11)$ & $<0.001^{*}$ \\
\hline Cutaneous & $56(6)$ & $320(6)$ & $320(7)$ & $718(12)$ & $<0.001^{*}$ \\
\hline Unknown & $112(12)$ & $564(11)$ & $536(12)$ & $720(12)$ & 0.15 \\
\hline Other & $62(6)$ & $337(7)$ & $308(7)$ & $384(6)$ & 0.61 \\
\hline Gynecologic & $3(<1)$ & $9(<1)$ & $16(<1)$ & $23(<1)$ & 0.20 \\
\hline \multicolumn{6}{|l|}{ Ethnicity } \\
\hline European & $720(75)$ & $4,013(77)$ & 3,387 (77) & $4,816(80)$ & $<0.001^{*}$ \\
\hline African American & $142(15)$ & $552(11)$ & $434(10)$ & $616(10)$ & $<0.001^{*}$ \\
\hline Hispanic & $35(4)$ & $223(4)$ & $197(5)$ & $185(3)$ & $0.001^{*}$ \\
\hline Asian & 17 (2) & $105(2)$ & 82 (2) & $50(<1)$ & $<0.001^{*}$ \\
\hline Native American & $8(<1)$ & $32(<1)$ & $36(<1)$ & $63(<1)$ & 0.10 \\
\hline Other & $42(4)$ & $294(6)$ & $266(6)$ & 297 (5) & $0.03^{*}$ \\
\hline
\end{tabular}


Table 3 Associations of underweight versus normal weight patients with mortality and management strategies in three multilevel logistic regression models

\begin{tabular}{|c|c|c|c|c|c|}
\hline \multirow[b]{2}{*}{ Characteristic } & \multicolumn{5}{|c|}{ Crude events } \\
\hline & $\begin{array}{l}\text { Normal } \\
\text { weight }\end{array}$ & $\begin{array}{l}\text { Under- } \\
\text { weight }\end{array}$ & Model $1^{a}$ & Model $2^{b}$ & Model $3^{C}$ \\
\hline & $n(\%)$ & $n(\%)$ & $\begin{array}{l}\text { aOR }(95 \% \mathrm{Cl}, \\
p \text {-value) }\end{array}$ & $\begin{array}{l}\text { aOR }(95 \% \mathrm{Cl}, \\
p \text {-value) }\end{array}$ & $\begin{array}{l}\text { aOR }(95 \% \mathrm{Cl}, \\
p \text {-value) }\end{array}$ \\
\hline ICU mortality & $\begin{array}{l}553 \\
(11)\end{array}$ & $\begin{array}{l}134 \\
(14)\end{array}$ & $\begin{array}{l}1.38 \\
(1.12-1.70, \\
0.002)\end{array}$ & $\begin{array}{l}1.54 \\
(1.15-2.06, \\
0.004)\end{array}$ & $\begin{array}{l}1.57 \\
(1.16-2.12 \\
0.003)\end{array}$ \\
\hline Management & - & - & - & - & - \\
\hline $\begin{array}{l}\text { Mechanical } \\
\text { ventilation }\end{array}$ & $\begin{array}{l}1175 \\
(23)\end{array}$ & $\begin{array}{l}221 \\
(23)\end{array}$ & $\begin{array}{l}1.05 \\
(0.88-1.25, \\
0.58)\end{array}$ & $\begin{array}{l}0.83 \\
(0.64-1.08, \\
0.17)\end{array}$ & - \\
\hline $\begin{array}{l}\text { Vasopressor } \\
\text { use }\end{array}$ & $\begin{array}{l}1708 \\
(33)\end{array}$ & $\begin{array}{l}291 \\
(30)\end{array}$ & $\begin{array}{l}0.87 \\
(0.74-1.02, \\
0.08)\end{array}$ & $\begin{array}{l}1.03 \\
(0.82-1.30, \\
0.80)\end{array}$ & - \\
\hline
\end{tabular}

aOR adjusted odds ratio, $B M I$ body mass index, $C /$ confidence interval, ICU in tensive care unit, SOFA sepsis-related organ failure assessment ${ }^{a}$ Model 1: ICU cluster as random effect

bModel 2: Model 1 plus patient level (age, creatinine concentration, ethnics, heart rate, infection focus, lactate concentration, sex, SOFA score) 'Model 3: Model 2 plus management strategies (mechanical ventilation, vasopressor use)

Table 4 Associations of overweight versus normal weight patients with mortality and management strategies in three multilevel logistic regression models

\begin{tabular}{|c|c|c|c|c|c|}
\hline \multirow[b]{2}{*}{ Characteristic } & \multicolumn{5}{|c|}{ Crude events } \\
\hline & $\begin{array}{l}\text { Normal } \\
\text { weight }\end{array}$ & $\begin{array}{l}\text { Over- } \\
\text { weight }\end{array}$ & Model $1^{\mathrm{a}}$ & Model $2^{b}$ & Model $3^{\mathrm{C}}$ \\
\hline & $n(\%)$ & $n(\%)$ & $\begin{array}{l}\text { aOR }(95 \% \mathrm{Cl} \\
p \text {-value) }\end{array}$ & $\begin{array}{l}\text { aOR }(95 \% \mathrm{Cl}, \\
p \text {-value) }\end{array}$ & $\begin{array}{l}\text { aOR }(95 \% \mathrm{Cl} \text {, } \\
p \text {-value) }\end{array}$ \\
\hline ICU mortality & $\begin{array}{l}553 \\
(11)\end{array}$ & $\begin{array}{l}437 \\
(10)\end{array}$ & $\begin{array}{l}0.93 \\
(0.81-1.06, \\
0.29)\end{array}$ & $\begin{array}{l}0.88 \\
(0.73-1.05, \\
0.16)\end{array}$ & $\begin{array}{l}0.88 \\
(0.73-1.06 \text {, } \\
0.18)\end{array}$ \\
\hline Management & - & - & - & - & - \\
\hline $\begin{array}{l}\text { Mechanical } \\
\text { ventilation }\end{array}$ & $\begin{array}{l}1175 \\
(23)\end{array}$ & $\begin{array}{l}935 \\
(21)\end{array}$ & $\begin{array}{l}0.93 \\
(0.84-1.03, \\
0.14)\end{array}$ & $\begin{array}{l}0.96 \\
(0.83-1.11 \\
0.58)\end{array}$ & - \\
\hline $\begin{array}{l}\text { Vasopressor } \\
\text { use }\end{array}$ & $\begin{array}{l}1708 \\
(33)\end{array}$ & $\begin{array}{l}1431 \\
(33)\end{array}$ & $\begin{array}{l}0.99 \\
(0.90-1.08, \\
0.79)\end{array}$ & $\begin{array}{l}0.94 \\
(0.83-1.08, \\
0.40)\end{array}$ & - \\
\hline
\end{tabular}

aOR adjusted odds ratio, $B M I$ body mass index, $C /$ confidence interval, $I C U$ intensive care unit, SOFA Sepsis-related organ failure assessment

${ }^{a}$ Model 1: ICU cluster as random effect

${ }^{\mathrm{b}}$ Model 2: Model 1 plus patient level (age, creatinine concentration, ethnics, heart rate, infection focus, lactate concentration, sex, SOFA score)

${ }^{C}$ Model 3: Model 2 plus management strategies (mechanical ventilation, vasopressor use)

in obese patients $(36 \%$ in obese patients vs. $22 \%$ in normal weight patients). Also, we found a significant trend towards higher Elixhauser comorbidity indices in underweight patients compared to all other BMI classes (see Table 1).

The amount of administered i.v. fluid per kg bodyweight was highest in underweight patients and lowest in obese patients (see Table $1 ; p<0.001$ ). The rates of patients receiving fluids $>30 \mathrm{ml} / \mathrm{kg} / \mathrm{h}$ in the first $24 \mathrm{~h}$ was higher in underweight compared to normal weight and obese patients ( $72 \%$ vs. $65 \%$ vs. $42 \%$;
Table 5 Associations of obese versus normal weight patients with mortality and management strategies in three multilevel logistic regression models

\begin{tabular}{|c|c|c|c|c|c|}
\hline & \multicolumn{5}{|c|}{ Crude events } \\
\hline \multirow[t]{2}{*}{ Characteristic } & $\begin{array}{l}\text { Normal } \\
\text { weight }\end{array}$ & Obese & Model $1^{\mathrm{a}}$ & Model $2^{b}$ & Model $3^{c}$ \\
\hline & $n(\%)$ & $n(\%)$ & $\begin{array}{l}\text { aOR }(95 \% \mathrm{Cl} \\
p \text {-value) }\end{array}$ & $\begin{array}{l}\text { aOR }(95 \% \mathrm{Cl}, \\
p \text {-value) }\end{array}$ & $\begin{array}{l}\text { a0R }(95 \% \mathrm{Cl}, \\
p \text {-value) }\end{array}$ \\
\hline ICU mortality & $\begin{array}{l}553 \\
(11)\end{array}$ & $\begin{array}{l}552 \\
(9)\end{array}$ & $\begin{array}{l}0.85 \\
(0.74-0.96 \text {, } \\
0.009)\end{array}$ & $\begin{array}{l}0.83 \\
(0.69-0.99 \text {, } \\
0.04)\end{array}$ & $\begin{array}{l}0.82 \\
(0.68-0.98, \\
0.03)\end{array}$ \\
\hline Management & - & - & - & - & - \\
\hline $\begin{array}{l}\text { Mechanical } \\
\text { ventilation }\end{array}$ & $\begin{array}{l}1175 \\
(23)\end{array}$ & $\begin{array}{l}1441 \\
(24)\end{array}$ & $\begin{array}{l}1.08 \\
(0.98-1.89, \\
0.11)\end{array}$ & $\begin{array}{l}1.14 \\
(0.99-1.32, \\
0.06)\end{array}$ & - \\
\hline $\begin{array}{l}\text { Vasopressor } \\
\text { use }\end{array}$ & $\begin{array}{l}1708 \\
(33)\end{array}$ & $\begin{array}{l}1977 \\
(33)\end{array}$ & $\begin{array}{l}0.996 \\
(0.913-1.086 \text {, } \\
0.93)\end{array}$ & $\begin{array}{l}0.97 \\
(0.86-1.10, \\
0.62)\end{array}$ & - \\
\hline \multicolumn{6}{|c|}{$\begin{array}{l}\text { aOR adjusted odds ratio, BMI body mass index, } C / \text { confidence interval, ICU in- } \\
\text { tensive care unit, SOFA Sepsis-related organ failure assessment } \\
\text { aModel 1: ICU cluster as random effect } \\
\text { bModel 2: Model } 1 \text { plus patient level (age, creatinine concentration, ethnics, } \\
\text { heart rate, infection focus, lactate concentration, sex, SOFA score) } \\
\text { 'Model 3: Model } 2 \text { plus management strategies (mechanical ventilation, } \\
\text { vasopressor use) }\end{array}$} \\
\hline
\end{tabular}

$p<0.001)$. We also observed differences in length of stay, with obese patients evidencing the lowest rate of short-term $(<72 \mathrm{~h})$ stays $(61 \%$ vs. $63 \%$ in normal weight patients). The management strategies with respect to vasopressor use and mechanical ventilation were similar across all BMI categories (see Tables 3 and 4 and 5).

Underweight patients evidenced higher rates of ICU mortality ( $14 \%$ vs. $11 \% ; p=0.002$ ), and this finding persisted after adjusting for both patient level characteristics in model 2 as well as in model 3 . We did not find differences regarding ICU mortality between normal weight and overweight patients $(11 \%$ vs. $10 \%$; see Table 4 ). Obese patients evidenced a lower risk of ICU mortality (9\% vs. $11 \%$; $p<0.001$ ) compared to normal weight, a finding which persisted after adjustment in all three models (see Table 5).

In the stratified analyses for underweight versus normal weight patients, we found a higher risk for ICU mortality in underweight patients above 65 years (aOR 1.52, 95\% CI 1.17-1.99), initial lactate concentration above $2.0 \mathrm{mmol} / \mathrm{L}$ (aOR 1.41, 95\%CI 1.03-1.93), those without vasopressor use (aOR 1.64, 95\% CI 1.22-2.22), mechanical ventilation (aOR 1.48, 95\% CI $1.12-1.94$ ), initial creatinine $<2.0 \mathrm{mg} / \mathrm{dL}$ (aOR 1.54 , 95\% CI $1.18-2.01$ ), SOFA score $<10$ points (aOR 1.48 , 95\% CI 1.15-1.90), heart rate above $110 \mathrm{bpm}$ (aOR 1.86, 95\% CI 1.33-2.59), and those with a pulmonary focus (aOR 1.38, 95\% CI 1.04-1.84). The corresponding Forest plot is given in Fig. 1.

In the stratified analyses for overweight versus normal weight patients, we found no differences in the odds of ICU mortality. The corresponding Forest plot is given in Fig. 2. In the stratified analyses for obese versus normal weight patients, we found 


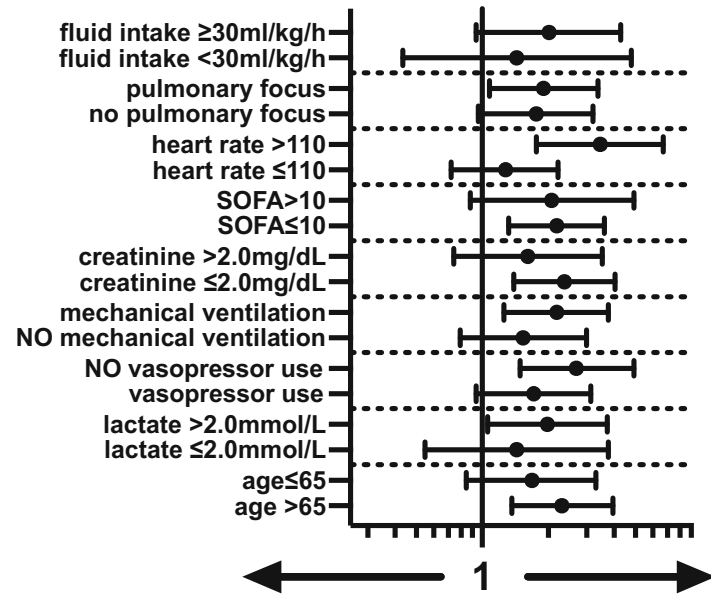

higher risk in normal weight

higher risk in underweight

Fig. 1 Forest plot of aOR of underweight versus normal weight patients for different subgroups according to model-1 (aOR 95\% Cl). Model 1: ICU cluster as random effect, aOR adjusted odds ratio, $\mathrm{Cl}$ confidence interval, SOFA sepsis-related organ failure assessment

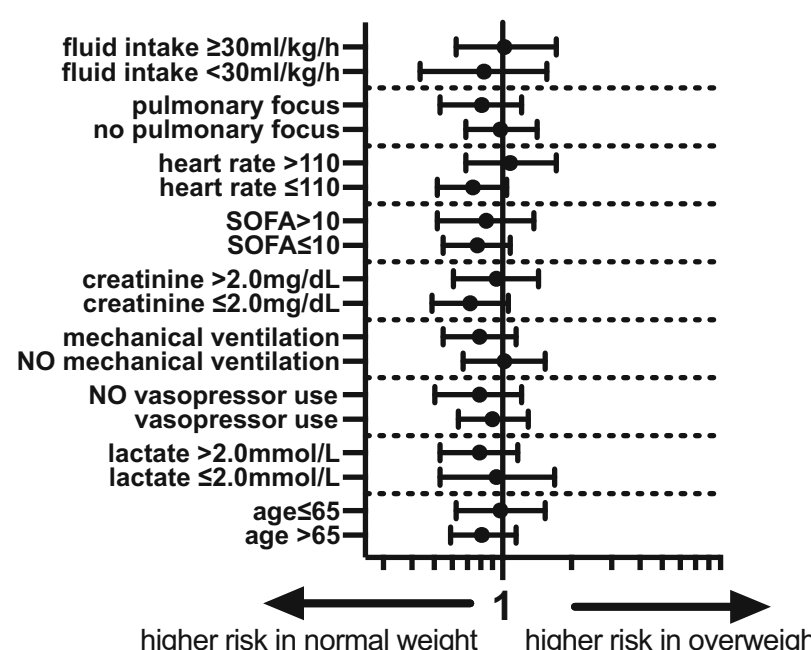

Fig. 2 Forest plot of aOR of overweight versus normal weight patients for different subgroups according to model-1 (aOR 95\% Cl). Model 1: ICU cluster as random effect, aOR adjusted odds ratio, $\mathrm{Cl}$ confidence interval, SOFA sepsis-related organ failure assessment

lower odds of ICU mortality in obese patients in the subgroup of patients aged $>65$ years (aOR $0.77,95 \%$ CI 0.65-0.91), patients without vasopressor use (aOR $0.78,95 \%$ CI $0.63-0.96)$, without mechanical ventilation (aOR 0.77, 95\% CI 0.65-0.92), initial creatinine below $2.0 \mathrm{mg} / \mathrm{dL}$ (aOR $0.74,95 \%$ CI $0.62-0.89$ ), SOFA score below 10 points (aOR $0.68,95 \%$ CI $0.58-0.81$ ) and heart rate below $110 \mathrm{bpm}$ (aOR $0.82,95 \% \mathrm{CI}$ 0.70-0.96). The corresponding Forest plot is given in Fig. 3.

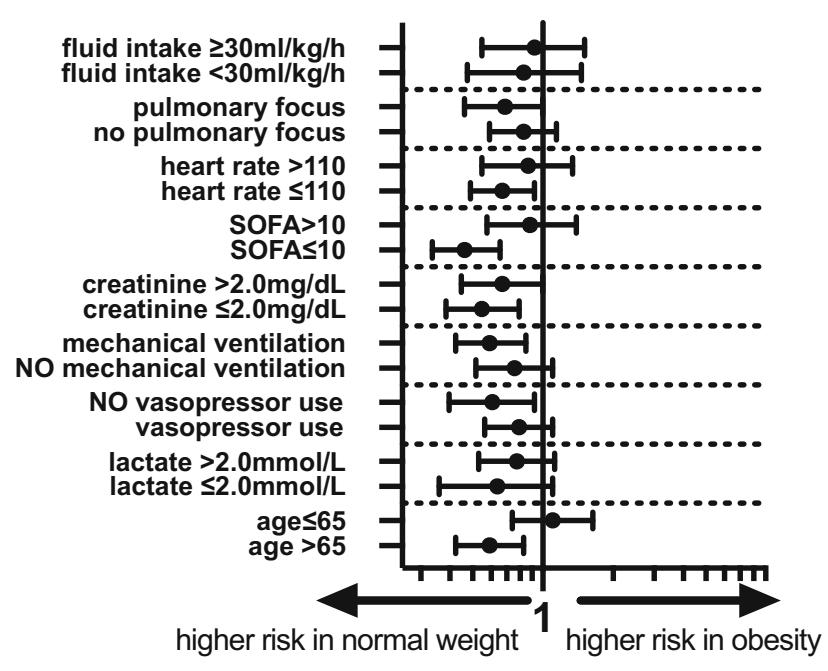

Fig. 3 Forest plot of aOR of obese versus normal weight patients for different subgroups according to model-1 (aOR $95 \% \mathrm{Cl}$ ). Model 1: ICU cluster as random effect, aOR adjusted odds ratio, $\mathrm{Cl}$ confidence interval, SOFA sepsis-related organ failure assessment

\section{Discussion}

In this study we could not find any differences regarding the use of organ replacement treatment in septic patients with different BMI classes; however, the amount of administered fluid relative to body weight was significantly higher in underweight patients than in normal or overweight individuals. Furthermore, we found an excess mortality of underweight patients, while obese patients showed higher survival rates. These findings could be demonstrated in univariate analysis as well as after extensive adjustment for clinically relevant confounders and were particularly relevant for individuals $>65$ years of age. To what extent different fluid management or other factors contributed to the observed robust association of underweight and excess mortality cannot be answered by this study.

The results of our analysis support the thesis of an obesity paradox in septic patients, indicating that obese patients do show higher survival rates compared to normal weight individuals. Similar results were recently shown by $\mathrm{Li}$ et al. in another large ( $n=5563$ ) single center US-based dataset [26]. They could show that not only short-term but also longerterm survival was higher in obese septic patients [26]. This so-called obesity paradox, initially unexpected from the perspective of the clinician (who is used to associate obesity with a higher risk of disease), was also suggested by previous meta-analyses of septic patients stratified for weight classes [20, 27]. It has also been described in patients with acute coronary syndrome or acute respiratory distress syndrome [28, 29]. On the other hand, Jagan et al. were able to show that the effect of BMI on mortality of septic patients in a cohort of 7967 patients was no longer detectable 
after adjustment for the severity of the acute disease (using acute physiology and chronic health evaluation III score) [30]. In our analysis, however, the effect remained detectable even after extensive adjustment.

The pathophysiological correlate of this observed obesity paradox is beyond the scope of this manuscript, and we can only speculate. A higher BMI was shown to be associated with higher levels of anti-inflammatory interleukins, which could ameliorate the excessive immune reaction, which is typical for sepsis [31]. Also, lipoproteins were shown to have a beneficial effect by binding lipid pathogens and sequestration of lipopolysaccharides (LPS) via (very) low-density lipoprotein receptors [32, 33]; however, other authors have not been able to prove a connection between BMI and the concentrations of cytokines in healthy volunteers [34]. Preclinical basic scientific data on the obesity paradox are also inconsistent [35]. The obesity paradox could have other reasons besides an altered cytokine response [36]. For example, the greater energy storage capacity of obese patients could be beneficial in acute consuming diseases, such as sepsis. Other authors have postulated that the effects of adipose tissue on the renin-angiotensin balance could contribute to better outcomes in obese patients $[36,37]$.

Nevertheless, despite the relatively robust data, one should remember that the available studies are primarily observational, and thus conclusions on causalities should only be drawn to a limited extent. The premise of the obesity paradox (namely that clinicians associate obesity with higher risk) could contribute to this effect: more obese patients could receive intensive care earlier, be treated more aggressively, and receive more intensive care from nursing staff [38]. Also, the observed effect could be primarily limited to overdominant subgroups, such as older patients, as the patients in many studies had a relatively high average age [19]. This consideration is also supported by our analysis: The protective effect of obesity was only detectable in the subgroup of older patients (>65 years) - perhaps in this subgroup obesity is an epiphenomenon for e.g. the absence of frailty (which is known to be associated with adverse outcomes), and the possible cardiometabolic risks of obesity are therefore less relevant $[39,40]$. On the other hand, these considerations remain speculative in any case, and in our analysis obesity in younger patients was not associated with excess mortality either.

In addition to higher survival rates in obese patients, we have demonstrated excess mortality in underweight patients. This effect is also in line with previous studies on this topic. Zhou et al. were recently able to show that a lower BMI was associated with worse outcome in patients with sepsis [17]. In contrast, a higher incidence of sepsis has been shown for overweight people in a study analyzing over 400,000 individuals [41]. Underweight was shown to be a risk factor in other conditions or after cardiac procedures [42]. As with obesity, the exact causality of the observed association between underweight and the mortality of septic patients is unclear. In contrast to the excess of protective factors in obese patients, it is logical to assume that due to the lack of adipose tissue, and therefore lower binding capacity of pathogenic lipids and LPS mentioned above in the text, underweight patients suffer from a higher mortality in sepsis. It is also known that underweight patients not only have a lean body mass but are frequently undersupplied with essential nutrients, like vitamins and trace elements, usually have less musculature (especially in the old, where it may indicate frailty), can suffer from underweight due to chronic diseases or addiction and often have a lower socioeconomic status [43]. This is also reflected in our work by the significant difference regarding Elixhauser comorbidity indices. The Elixhauser comorbidity index has been validated in its different versions by various authors in the past, controls for comorbidities not directly related to the admission diagnosis, and correlates well with in-hospital mortality. It is a useful marker to summarize multiple pre-existing conditions and to estimate pre-existing morbidity [44]. Furthermore, ethnic factors certainly play a role, as in our study a higher proportion of individuals with European ethnicity was found in obese patients, whereas more Asian patients were observed in the underweight group. Ethnical differences in body tissue composition are well known [45].

An important point would be to provide functional assessments in ICU databases in addition to common intensive care scores in the future. For example, in addition to baseline data such as BMI, it would be important to perform a functional assessment for activities of daily life (ADL, e.g. by Katz index), but also with respect to nutritional status (e.g., by mini nutritional status) and to analyze data accordingly. In the future, this could help to clarify the debate regarding the optimal BMI, since old people are often identified as undernourished despite a normal BMI [46]. Another important point is that this study relies on data from the USA and thus may not be equally applicable to all other countries. For example, the USA remains the high-income country with the highest average BMI, although various countries around the globe follow this trend and Europe also struggles with obesity as a major health challenge [47]. Nevertheless, there are two other important points to consider here: as mentioned earlier, BMI alone is probably not sufficient to fully illuminate the issue, as nutritional status certainly plays a relevant role and here also differences between different countries exist. Another limitation for outcome analyses between distinct countries with currently available databases are different definitions of sepsis and septic shock. In the future, more accurate statements should be possible with newer databases that use the current sepsis-3 definition [47]. 
Ward et al. recently demonstrated that suboptimal fluid management could also contribute to this effect, especially in underweight patients [15]. In our study we could detect significant differences in the fluid management of septic patients in the different BMI classes. In the stratified analysis, the excess mortality of underweight patients was also detectable, especially in those patients who received $>30 \mathrm{ml} / \mathrm{kg} / \mathrm{h}$ of fluids in the first $24 \mathrm{~h}$. On the other hand, the amount of fluid, even in relation to body weight, can only be assessed to a limited extent in isolation from the specific clinical situation. The cut-off of $30 \mathrm{ml} / \mathrm{kg} / 24 \mathrm{~h}$ is also controversial [48]. In addition, however, the greatest limitation in this respect is the high number of missing values $(n=8276)$ in this variable. We have deliberately decided against imputations, since our clinical experience shows that fluid management is handled very individually. Our finding that underweight patients have excess mortality and also receive a high relative amount of fluid therefore remains descriptive.

We hope that our exploratory analysis of nearly 16,000 septic patients will motivate clinicians to pay special attention to the counterintuitive high-risk group of underweight patients with sepsis. We also hope that our results will help the scientific community to design prospective studies that will shed more light on the impact of BMI in septic patients and optimal fluid management.

\section{Limitations}

This is a retrospective analysis or a dataset which was not a priori set up to investigate the present research question, and our results are therefore limited to thesis-generating character. Although we fitted several regression models and adjusted them for various potential confounding factors, we cannot rule out the possibility that other aspects that may not be included in the data set may ultimately influence the outcome. As discussed above, obese patients might be admitted to critical care earlier compared to other patients, and we cannot adjust for this potential selection bias. Another limitation of our analysis is the lack of longterm data or functional outcomes of the patients. This also limits an analysis regarding the ideal body weight in terms of outcome, as probably functional and nutritional status would be relevant confounders here. Also, data on patient management are not available in greatest detail. We have already commented on the high number of missing values in the data on fluid substitution. We would like to emphasize again that this could lead to a selection bias. Finally, the low mortality in relation to other studies must be stated as a limitation. We have selected the patients using an established method and also observed similar results in the sensitivity analyses for patients with shock (increased lactate, need for vasoactive substances, high SOFA score).

\section{Conclusion}

In this cohort, underweight $\left(\mathrm{BMI}<18.5 \mathrm{~kg} / \mathrm{m}^{2}\right)$ was associated with a higher mortality in septic patients, whereas a better outcome was observed in obese patients. Our analysis thus supports the thesis of the obesity paradox, and also indicates that in older individuals ( $>65$ years) BMI could be a surrogate parameter for frailty, as in that age group significant differences regarding outcome were shown. To what extent different fluid management strategies or other factors contributed to the observed robust association of underweight and excess mortality cannot be answered by means of this study.

Funding No (industry) sponsorship has been received for this investigator-initiated study.

Author Contribution Conceptualization: Thomas Danninger and Bernhard Wernly. Methodology: Bernhard Wernly, Behrooz Mamandipoor and Venet Osmani. Formal analysis and investigation: Bernhard Wernly, Behrooz Mamandipoor and Venet Osmani. Writing-original draft preparation: Thomas Danninger, Richard Rezar and Bernhard Wernly. Writing-review and editing: Richard Rezar and Bernhard Wernly. Supervision: Daniel Dankl, Andreas Koköfer and Christian Jung.

Funding Open access funding provided by Paracelsus Medical University.

Conflict of interest T. Danninger, R. Rezar, B. Mamandipoor, D. Dankl, A. Koköfer, C. Jung, B. Wernly and V. Osmani declare that they have no competing interests.

Open Access This article is licensed under a Creative Commons Attribution 4.0 International License, which permits use, sharing, adaptation, distribution and reproduction in any medium or format, as long as you give appropriate credit to the original author(s) and the source, provide a link to the Creative Commons licence, and indicate if changes were made. The images or other third party material in this article are included in the article's Creative Commons licence, unless indicated otherwise in a credit line to the material. If material is not included in the article's Creative Commons licence and your intended use is not permitted by statutory regulation or exceeds the permitted use, you will need to obtain permission directly from the copyright holder. To view a copy of this licence, visit http://creativecommons.org/licenses/by/4.0/.

\section{References}

1. McLellan F. Obesity rising to alarming levels around the world. Lancet. 2002;359(9315):1412.

2. Festa A, D'Agostino R Jr., Williams K, Karter AJ, MayerDavis EJ, Tracy RP, et al. The relation of body fat mass and distribution to markers of chronic inflammation. Int JObes Relat Metab Disord. 2001;25(10):1407-15.

3. Dellinger RP, Levy MM, Rhodes A, Annane D, Gerlach H, Opal SM, et al. Surviving sepsis campaign: international guidelines for management of severe sepsis and septic shock: 2012. CritCare Med. 2013;41(2):580-637.

4. Ghilotti F, Bellocco R, Ye W, Adami HO, Trolle Lagerros Y. Obesity and risk of infections: results from men and women 
in the Swedish National March Cohort. Int J Epidemiol. 2019;48(6):1783-94.

5. Wang HE, Griffin R, Judd S, Shapiro NI, Safford MM. Obesity and risk of sepsis: a population-based cohort study. Obesity (Silver Spring). 2013;21(12):E762-E9.

6. Sakr Y, Moreira CL, Rhodes A, Ferguson ND, Kleinpell R, Pickkers P, et al. The impact of hospital and ICU organizational factors on outcome in critically ill patients: results from the extended prevalence of infection in intensive care study. Crit Care Med. 2015;43(3):519-26.

7. Wernly B, Heramvand N, Masyuk M, Rezar R, Bruno RR, Kelm M, et al. Acidosis predicts mortality independently from hyperlactatemia in patients with sepsis. Eur J Intern Med. 2020;76:76-81.

8. Wernly B, Bruno RR, Kelm M, Boumendil A, Morandi A, Andersen FH, et al. Sex-specific outcome disparities in very old patients admitted to intensive care medicine: a propensity matched analysis. Sci Rep. 2020;10(1):18671.

9. Wernly B, Bruno RR, Mamandipoor B, JungC, Osmani V.Sexspecific outcomes and management in critically ill septic patients. EurJ Intern Med. 2020;83:74-77.

10. Wernly B, Mamandipoor B, Baldia P, Jung C, Osmani V. Machinelearning predicts mortality in septic patients using only routinely available ABG variables: a multi-centre evaluation. Int J Med Inform. 2020;145:104312.

11. Moss SR, Prescott HC. Current controversies in sepsis management. Semin Respir Crit Care Med. 2019;40(5):594-603.

12. Vincent JL, Marshall JC, Namendys-Silva SA, Francois B, Martin-Loeches I, Lipman J, et al. Assessment of the worldwide burden of critical illness: the intensive care over nations (ICON) audit. Lancet Respir Med. 2014;2(5):380-6.

13. van Vught LA, Klein Klouwenberg PM, Spitoni C, Scicluna BP, Wiewel MA, Horn J, et al. Incidence, risk factors, and attributable mortality of secondary infections in the intensive care unit after admission for sepsis. JAMA. 2016;315(14):1469-79.

14. Prescott HC, Angus DC. Enhancing recovery from sepsis: a review. JAMA. 2018;319(1):62-75.

15. Ward MA, Kuttab HI, Lykins VJ, Wroblewski K, Hughes MD, Keast EP, et al. The effect of body mass index and weightadjusted fluid dosing on mortality in sepsis. J Intensive Care Med. 2020; https://doi.org/10.1177/0885066620973917.

16. Lee SM, Kang JW, Jo YH, Kim K, Lee JH, Lee J, et al. Underweight is associated with mortality in patients with severe sepsis and septic shock. Intensive Care Med Exp. 2015;3(1):A876.

17. Zhou Q, Wang M, Li S, Zhang J, Ma Q, Ding Y, et al. Impact of body mass index on survival of medical patients with sepsis: a prospective cohort study in a university hospital in China. BMJ Open. 2018;8(9):e21979.

18. Trivedi V, Bavishi C, Jean R. Impact of obesity on sepsis mortality: a systematic review. JCrit Care. 2015;30(3):518-24.

19. Prescott HC, Chang VW, O'Brien JM Jr., Langa KM, Iwashyna TJ. Obesity and 1-year outcomes in older Americans with severe sepsis. Crit Care Med. 2014;42(8):1766-74.

20. Hogue CW Jr., Stearns JD, Colantuoni E, Robinson KA, Stierer T, Mitter N, et al. The impact of obesity on outcomes after critical illness: a meta-analysis. Intensive Care Med. 2009;35(7):1152-70.

21. Pepper DJ, DemirkaleCY, Sun J, RheeC, Fram D, Eichacker P, et al. Does obesity protect against death in sepsis? A retrospective cohort study of 55,038 adult patients. Crit Care Med. 2019;47(5):643-50.

22. Amundson DE, Djurkovic S, Matwiyoff GN. The obesity paradox. Crit Care Clin. 2010;26(4):583-96.

23. Pollard TJ, Johnson AEW, Raffa JD, Celi LA, Mark RG, Badawi O. The eICU Collaborative Research Database, a freely available multi-center database for critical care research. SciData. 2018;5:180178.

24. Elixhauser A, Steiner C, Harris DR, Coffey RM. Comorbidity measures for use with administrative data. Med Care. 1998;36(1):8-27.

25. Agency for Healthcare Research and Quality. Elixhauser comorbidity software refined for ICD-10-CM Healthcare Cost and Utilization Project (HCUP). 2020. www.hcup-us. ahrq.gov/toolssoftware/comorbidityicd10/comorbidity_ icd10.jsp. Accessed: 22 June 2021.

26. Li S, Hu X, Xu J, Huang F, Guo Z, Tong L, et al. Increased body mass index linked to greater short- and long-term survival in sepsis patients: a retrospective analysis of a large clinical database. Int J InfectDis. 2019;87:109-16.

27. Wang S, Liu X, Chen Q, Liu C, Huang C, Fang X. The role of increased body mass index in outcomes of sepsis: a systematic review and meta-analysis. BMC Anesthesiol. 2017;17(1):118.

28. Niedziela J, Hudzik B, Niedziela N, Gasior M, Gierlotka M, Wasilewski J, et al. The obesity paradox in acute coronary syndrome: a meta-analysis. Eur J Epidemiol. 2014;29(11):801-12.

29. Ni YN, Luo J, Yu H, Wang YW, Hu YH, Liu D, et al. Can body mass index predict clinical outcomes for patients with acute lung injury/acute respiratory distress syndrome? A metaanalysis. Crit Care. 2017;21(1):36.

30. Jagan N, Morrow LE, Walters RW, Plambeck RW, Wallen TJ, Patel TM, et al. Sepsis and the obesity paradox: size matters in more than one way. CritCare Med. 2020;48(9):e776-e82.

31. Zampieri FG, Jacob V, Barbeiro HV, Pinheiro da Silva F, de Souza HP. Influence of body mass index on inflammatory profile at admission in critically ill septic patients. Int J Inflam. 2015;2015:734857.

32. Shimada T, Topchiy E, Leung AKK, Kong HJ, Genga KR, Boyd JH, et al. Very low density lipoprotein receptor sequesters lipopolysaccharide into adipose tissue during sepsis. Crit Care Med. 2020;48(1):41-8.

33. Walley KR, Thain KR, Russell JA, Reilly MP, Meyer NJ, Ferguson JF, et al. PCSK9 is a critical regulator of the innate immune response and septic shock outcome. Sci Transl Med. 2014;6(258):258ra143.

34. van Eijk LT, van der Pluijm RW, Ramakers BP, Dorresteijn MJ, van der Hoeven JG, Kox M, et al. Body mass index is not associated with cytokine induction during experimental human endotoxemia. Innate Immun. 2014;20(1):61-7.

35. Xu W, Pepper D, Sun J, Welsh J, Cui X, Eichacker PQ. The effects of obesity on outcome in preclinical animal models of infection and sepsis: a systematic review and metaanalysis. J Obes. 2020;2020:1508764.

36. Ng PY, Eikermann M. The obesity conundrum in sepsis. BMCAnesthesiol. 2017;17(1):147.

37. Kershaw EE, Flier JS. Adipose tissue as an endocrine organ. J Clin Endocrinol Metab. 2004;89(6):2548-56.

38. Arabi YM, Dara SI, Tamim HM, Rishu AH, Bouchama A, Khedr MK, et al. Clinical characteristics, sepsis interventions and outcomes in the obese patients with septic shock: an international multicenter cohort study. Crit Care. 2013;17(2):R72.

39. Guidet B, de Lange DW, Boumendil A, Leaver S, Watson X, Boulanger $\mathrm{C}$, et al. The contribution of frailty, cognition, activity of daily life and comorbidities on outcome in acutely admitted patients over 80 years in European ICUs: the VIP2 study. Intensive Care Med. 2020;46(1):57-69.

40. Flaatten H, De Lange DW, Morandi A, Andersen FH, Artigas A, Bertolini G, et al. The impact of frailty on ICU and 30day mortality and the level of care in very elderly patients $(\geq$ 80 years). Intensive Care Med. 2017;43(12):1820-8. 
41. Weng L, Fan J, Yu C, Guo Y, Bian Z, Wei Y, et al. Bodymass index and long-term risk of sepsis-related mortality: a population-based cohort study of 0.5 million Chinese adults. Crit Care. 2020;24(1):534.

42. Kalbacher D, Tigges E, Boekstegers P, Puls M, Plicht B, Eggebrecht $\mathrm{H}$, et al. Underweight is associated with inferior short and long-term outcomes after MitraClip implantation: results from the German TRAnscatheter mitral valve interventions (TRAMI) registry. AmHeartJ.2020;222:73-82.

43. Little M, Humphries S, Patel K, Dewey C. Factors associated with BMI, underweight, overweight, and obesity among adults in a population of rural south India: a cross-sectional study. BMC Obes. 2016;3:12.

44. Moore BJ, White S, Washington R, Coenen N, Elixhauser A. Identifying increased risk of readmission and in-hospital mortality using hospital administrative data: the AHRQ Elixhauser comorbidity index. Med Care. 2017;55(7):698-705.
45. Oami T, Karasawa S, Shimada T, Nakada TA, Abe T, Ogura H, et al. Association between low body mass index and increased 28-day mortality of severe sepsis in Japanese cohorts. Sci Rep. 2021;11(1):1615.

46. Bahat G, Tufan F, Saka B, Akin S, Ozkaya H, Yucel N, et al. Which body mass index (BMI) is better in the elderly for functional status? Arch Gerontol Geriatr. 2012;54(1):78-81.

47. Marques A, Peralta M, Naia A, Loureiro N, de Matos MG. Prevalence of adult overweight and obesity in 20 European countries, 2014. Eur J Public Health. 2018;28(2):295-300.

48. Marik PE, Byrne L, van Haren F. Fluid resuscitation in sepsis: the great $30 \mathrm{~mL}$ per $\mathrm{kg}$ hoax. J Thorac Dis. 2020;12(S1):S37-S47.

Publisher's Note Springer Nature remains neutral with regard to jurisdictional claims in published maps and institutional affiliations. 